\section{The nurse's role in managing treatment-induced nausea and vomiting}

\section{By Margaret Fitch}

\begin{abstract}
Patients have reported that nausea and vomiting are their first concern when receiving chemotherapy. The consequences of inadequately controlled nausea and vomiting range from minor discomfort to dose-limiting toxicity. Nurses have a key role to play in helping patients and families manage the distress associated with treatment side effects. Astute assessment, collaborative planning and developing a partnership with the patient are key aspects of the nurse's role. The relationship the murse develops with the patient is the avenue for understanding the patient's perspective and ensuring treatment goals are mutually agreeable.
\end{abstract}

Patients have reported that nausea and vomiting are their first concem while receiving chemotherapy (Coates $\mathrm{ct}$ al, 1983) and are perceived as the most distressing and troublesome symptoms. Nausea and vomiting are among the most frequent symptoms associated with cancer and cancer treatment (Richardson, 1988). It has been estimated that nausea and vomiting occur in most patients receiving chemotherapy and by the majority of patients receiving radiation to the brain and/or total body (Eyre, 1984; Donaldson, 1984). In addition, it remains a very distressing side effect for up to $30 \%$ of the individuals who undergo chemotherapy despite antiemetic therapy (Craig, 1987). The consequences of inadequately controlled nausea and vomiting range from minor discomfort to dose-limiting toxicity.

Partly as a result of the side effects, patients may request reductions in treatment, discontinue treatment or try unproven remedies. Non-adherence to the treatment regimen could hinder the success of potentially curative treatments (Bonadonna, 1981; Merrifield, 1989; Hoagland, 1983). Penta et al (1983) found that $85 \%$ of a group of physicians who treat patients with cancer reported that up to $10 \%$ to $15 \%$ of their patients refuse chemotherapy because of nausea and vomiting at some point during their care. Laszlo estimated that $30 \%$ of patients refuse chemotherapy because of nausea and vomiting while an additional $20 \%$ delay treatment or miss clinic appointments because of fear of nausea and vomiting (Laszlo, 1983). Levine reported that non-compliance with oral

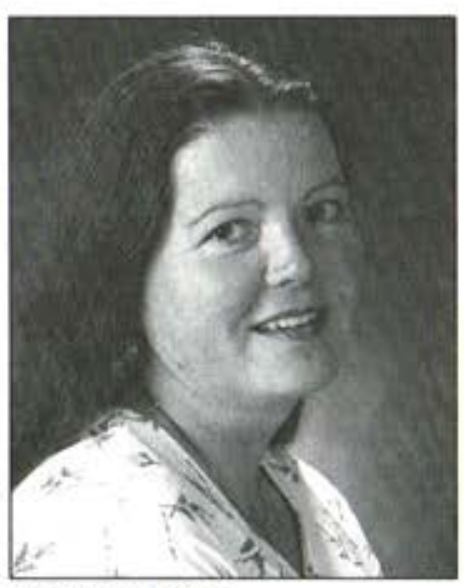

Margaret Fitch self-administered medication among patients with hematologic cancers was a problem more than $50 \%$ of the time and appointment-keeping approximately $15 \%$ of the time (Levine, 1987).

Richardson (1988), in a study of 107 patients with hematological malignancies six months after diagnosis, found it was not the occurrence of adverse effects by themselves that contribute to specific non-compliance, but rather it was the difficulty in managing them. Nerenz (1982) also reported that patients who experienced either unsuccessful attempts to cope with side effects or no attempts to cope at all had greater distress than those who coped successfully. Hence, symptom management is a critical aspect of care.

Nurses have a key role to play in the management of treatment-induced nausea and vomiting. Their assessment and efforts to design a tailor-made care plan for individuals can make a significant contribution to the effective management of the distress associated with emesis. This article outlines key activities for nurses in the effective management of this complex symptom.

\section{Patterns of nausea and vomiting}

Nausea and vomiting are separate entities and the person may experience either or both. Neurological stimulation may occur via several pathways. Stimulation of a complex reflex organized by the vomiting centre results in the experience of nausea and/or vomiting (Grant, 1985; Yasko, 1985).

Acute nausea and vomiting in the first 24 hours following chemotherapy have been well described and are known to be related to the emetogenicity of chemotherapy, prior experience and antiemetic regimens (Rhodes et al, 1985; Rhodes $\mathrm{et}$ al, 1987; Wickham, 1989). The pattern of acute nausea and vomiting experienced by the majority of patients receiving chemotherapy by bolus administration (infused in less than one hour) is the initiation of nausea and vomiting within the first few minutes or hours. The nausea reaches a peak level within four to 10 hours and then begins to subside in 12 to 24 hours. If the administration is via continuous infusion over 24 hours or several days, the pattern is slightly different. Nausea and vomiting begin in the same fashion as with the bolus dose, peak during the first 24 hours and gradually diminish during the remainder of the infusion period. By day four to five the patient seems to have built a tolerance to chemotherapy. However, this tolerance is lost prior to the next administration.

Understanding of delayed nausea and vomiting, that which occurs up to seven days following the administration of chemotherapy, is increasing. Kris et al (1985) noted that up to $60 \%$ to $80 \%$ of patients

\section{LE RÔLE DE L'INFIRMIĖRE DANS LA GESTION DES NAUSÉES ET DES VOMISSEMENTS INDUITS PAR LE TRAITEMENT}

\section{ABRÉGÉ}

Les patients rapportent que les nausées et les vomissements sont leurs principaux soucis quand ils sont traités par chimiothérapie. Des nausées et vomissements mal contrôlés peuvent avoir des conséquences allant d'une gêne passagère ả une toxicité qui amènera à limiter les doses. Les infirmières sont appelées à jouer un rôle clé pour aider leurs patients et les familles à gérer la détresse qui accompagne les effèts secondaires du traitement. Une évaluation astucieuse, une planification mettant l'accent sur la collaboration et le développement d'un partenariat avec les patients font partie des composantes clés du rôle de l'infirmière. Les rapports que l'infimière entretient avec les patients sont la voie qui lui permettra de comprendre la perspective des patients et de veiller à ce que le traitement ait des objectifs sur lesquels les deux parties sont d'accord.

Margaret Fitch, RN, $\mathrm{PhD}$, is oncology nurse researcher in the Comprehensive Cancer Program of the Toronto-Bayview Regional Cancer Centre and Sunnybrook Health Sciences Centre, Toronto. 
who had received high dose cisplatin experienced some nausca and vomiting commencing 24 or more hours after chemotherapy and lasting up to 120 hours. A significant number of these patients had experienced no nausea and vomiting during the initial 24 hours following the cisplatin administration. Similar patterns were noted for other treatment regimens. Lindley (1989) found $64 \%$ of patients experienced nausea and $38 \%$ experienced vomiting during a five-day study following administration of a variety of chemotherapy agents. Nausea and vomiting were confined to day one only in $26 \%$ and $40 \%$ of patients, respectively. Twenty-two per cent and $27 \%$ of patients reported nausea and vomiting both for the acute and delayed. A significant percentage of patients reported nausea and vomiting during the delayed period only ( $52 \%$ and $33 \%$ respectively).

Anticipatory nausea, and somewhat less often anticipatory vomiting, have been experienced by $25 \%$ to $67 \%$ of patients receiving chemotherapy within four courses of chemotherapy (Wickham, 1989). With this phenomenon, cues associated with chemotherapy administration (eg. sight of the hospital, sight of the chemotherapy nurse or doctor, smell of rubbing alcohol) evoke the symptoms. Other factors that are suspected of influencing anticipatory nausea and vomiting in combination with severe post-chemotherapy symptoms include being younger in age, being female, experiencing self-reported anxiety, and having received chemotherapy in the past (Yasko, 1985). In addition, anticipatory nausea and vomiting may persist after treatment with chemotherapy is completed. In one study, $50 \%$ of patients who had experienced anticipatory nausea and vomiting with chemotherapy still were experiencing some nausea 2.5 years later (Cella et al, 1986).

\section{Consequences of nausea and vomiting}

There are consequences of poorly controlled nausea and vomiting for the individual, in addition to the consequence of not receiving potentially curable therapy. Personal discomfort and physiological complications, together with their subsequent impact on quality of life, create significant challenges for the patient and family to manage.

Prolonged or excessive vomiting can result in inadequate oral intake and exacerbation of antineoplastic toxicity, metabolic disturbances and anorexia and psychologic distress (Ingle et al, 1984, Nerenz et al, 1982). In turn, this may decrease the patient's performance status and tolerance for further chemotherapy. An infrequent complication is Mallory-Weiss Syndrome, in which excessive retching causes bleeding esophageal tears (Fishman, 1983). Repeat vomiting may also result in skeletal fractures (Whitehead, 1975).

Nutritional consequences of nausea, vomiting and anorexia include weight loss and nutritional depletion from the decrease in food intake below metabolic need and/or alterations in host metabolism (Holroyde, 1986; Kaempfer, 1986). A weight loss of more than five per cent in four weeks or more than $10 \%$ in six months is considered severe (Garry, 1980). When severe weight loss is associated with major stress such as surgery, the weight loss may be life-threatening. The weight loss is accompanicd by a depressed immune status and hence decreased protection against infection. In the surgical patients, decreased wound healing may result. Other patients may suffer from the complex syndrome of cachexia, a profound systemic abnormality often associated with late stage cancer characterized by weakness, wasting, depletion, redistribution of host components, hormonal abnormalities and progressive failure of vital function (Lindsey, 1982).

\section{Nausea and vomiting influence quality of life}

Nausea and vomiting influence performance of daily living activities. In one study, $40 \%$ of the patients surveyed reported that nausea and vomiting interrupted their ability to perform daily activities and $23 \%$ of the patients found the symptoms so debilitating that they went to bed (Kennedy, 1981). Lindley et al (in press) detailed a range of daily activities patients reported they were unable to perform for an interval because of nausea and vomiting: $12 \%$ unable to take care of themselves, $19 \%$ unable to take care of others, $22 \%$ unable to prepare meals, $47 \%$ unable to eat, $33 \%$ unable to run errands, $35 \%$ unable to perform household tasks and $33 \%$ unable to engage in activities with friends. In another study, patients on complex chemotherapy regimens reported more nausea, greater difficulty dealing with the nausea, and feeling more disabled by the nausea than patients on less complex regimens (Richardson, 1988). In general, younger patients experiencing these complex regimens were more likely than older patients to have difficulty with nausea, appetite loss, infection and weakness and to feel disabled due to these effects (Richardson, 1988). It is hypothesized this could relate to the interruption chemotherapy causes in busy active lives of the younger individuals.

Patients' descriptions of their experiences with treatment-induced nausea and vomiting paint a clear picture of the impact they feel. The following comments were made by individuals who experienced treatment-induced nausea and vomiting. The individuals range in age and diagnostic site.

this is worse than the disease

.it's an indescribably horrible experience...it 's like going and

getting a shot of stomach fu every day.

.imagine vomiting for five hours. You feel tumed inside out...everything hurts.

I'm too ill to enjoy anything - too ill to work, too wiped out to lead a normal life...it's half living..

I can't stand the side effects any more. I'd rather die than be sick like this for six more months.

.the treatment does terrible things...I could talk about the treatments and get sick - actually throw up thinking about them and I haven't had any lately.

The nausea and vomiting can influence the quality of patients' lives. The physical effects of nausea and vomiting together with the accompanying weakness and fatigue can restrict activity and alter various aspects of one's abilities to fulfil usual roles at work or at home. It is most difficult to cook meals for a family when the smell of food cvokes a feeling of nausea. Nausea can influence one's ability to concentrate on work-related matters and the need to remain close to washroom facilities may preclude going to a public work environment. Travel via any means may be troublesome for a time. Some people are embarrassed by the indignity of vomiting and would prefer that not even their family see their discomfort, let alone colleagues at work. For periods of time, the smell and/or sight of food can be troublesome and lead people to tum away from social activities such as dinner at a friend's home or in a restaurant. Delight in favourite foods can be lost. Usual forms of recreation and exereise may also be precluded.

For some individuals experiencing nausea and vomiting, a pervasive sense of being powerless, being out of control and helpless, can emerge. In tum, these feelings can contribute to perspectives of hopelessness and despair. Some individuals will mention a great sense of "being alone" in their agony. Especially if they are at home, away from the hospital and/or clinic, both they and their family feel a sense of isolation. They wonder if there is anything more they can do to deal with the nausea and vomiting or if what they are experiencing is normal. Their fear and anxiety no doubt contribute to the sense of feeling out of control.

Patients also may find that their need for help from others during bouts of vomiting contributes to reduced self-image. Particularly if individuals are used to being independent, doing things for themselves and managing in their own way, finding a comfort level with accepting help from either family or friends can be a challenge. The bouts of nausea and vomiting can easily disrupt a family's schedule and create a good deal of extra work in terms of laundering and cleaning. The idea that the episode could be repeated at regular intervals for an uncertain period of time can be overwhelming. People describe the side effects as ruling their lives, their emotions and their bodies.

Self image may also be influenced by any wasting or weight loss. These are visible signs that serve to remind the individual, the family and others about the disease and the uncertainty of the future. Functional self-image and feelings of self-worth can be altered if individuals are unable to work, to engage in family activities or to supply family needs (i.c., financial, houschold duties) in their usual fashion. For some, being unable to effectively carry out their professional and/or volunteer roles 
and responsibilities has a great impact.

If chemotherapy/radiation protocols demand hospitalization for hydration and nutritional support, individuals experience separation from family and from the familiarity of home. In addition, some patients must travel a distance to be hospitalized and this may preclude visits by family members. If family members are able to accompany the patient, issues surrounding travel and accommodation expenses can arise. Repeat hospitalizations may also threaten job security or medical insurance coverage for individuals.

It should also be noted that a number of antiemetic drugs in current use have certain side effects including sedation, "highs", agitation, and extra pyramidal symptoms. Patients can experience muscle spasms and stiffness and report feeling a sense of unreality and profound agitation. For some, these are so troublesome they prefer some nausea and vomiting or they decline further chemotherapy. Patients may have to try a variety of antiemetic medications before a measure of success is realized. Although individuals may achieve a reasonable control, they experience much discomfort beforehand as the various combinations of antiemetic are tried. It would be preferable if patients did not have to experience these difficulties.

Thus nausea and vomiting induced by cancer therapy can have an impact on physical, social and emotional aspects of an individual's life. Dealing with the side effects presents major challenges to patients and family members.

\section{Managing nausea and vomiting}

Effective management of nausea and vomiting can enhance cancer patients' quality of life and their ability to cope and to continue receiving cancer treatment. Good symptom control is an important consideration in the overall care of the individual patient and, therefore, is of particular importance to the cancer nurse. The nurse is usually the key person dealing with the frequent side effect of emesis. Nurses are often the ones to recognize a problem exists, to deal with the practicalities of the patient's needs and to initiate activities to change care approaches. Nurses have clearly identified the importance of their role in managing these symptoms and the potential for their impact upon client well-being (Oberst, 1978; Pritchard, 1989).

The relief of treatment-induced nausea and vomiting is a complex clinical problem. It must be handled in the context of the full range of issues presented by the reality of the cancer diagnosis, the treatment plan, the individual patient variability in responding to therapy. Cancer and its treatment affect patients and family in many ways and nurses must constantly look for approaches to offset the myriad changes that may face a patient and his/her family

Of critical importance to successful management of patients' symptoms is teamwork between nurses, physicians and patients. By developing and implementing collaborative treatment and care plans, the potential for improved patient outcomes is created (Engelking-Steele, 1984). Devising such a plan requires that the patient is involved as a partner, mutually agreed upon goals are established and close attention is paid to patient and family preferences.

Communication is key to understanding and fulfilling these goals. Patients play an integral role in communicating their needs, problems and desires to the nurse and physician. The role of health professionals is to provide the knowledge, motivation and tools for patients to care for themselves appropriately.

During the initial contact with a patient and the family, the nurse begins to gather information and to form a trusting relationship with the patient. The patient and family must feel the environment is supportive and that they can be comfortable talking about their fears and concerns. As this relationship unfolds, it places the nurse in a unique position to truly understand the patient's perspectives and feelings.

\section{The role of the nurse}

Once a diagnosis of cancer has been confirmed and a specific treatment plan established, the nurse can initiate a focused, indepth assessment with the patient related to the potential problems with the treatment (Engelking, 1984). The appropriate educational process can also begin at this time for there is opportunity to discuss the nature of the particular treatment regimen, the problems that may arise and resources available to assist the patient and family.

A key role for the nurse at this time is to anticipate the likelihood of nausea and vomiting and work to prevent its occurrence. The nursing assessment needs to include such data as:

- learning needs of the patient and family regarding the disease, treatment, nausea, vomiting

- expectations and misunderstandings or myths about symptoms

- stresses evident in life that may impact on the ability to manage the treatment toxicities

- past experiences with nausea, vomiting

- patterns of sleep, rest, pain, nutrition/eating

- risk factors: mouth/throat disorders, fatigue, female, age, alcohol abuse

- anti-emetics used and their effectiveness and other approaches used to minimize nausea and vomiting.

The nurse needs to use a combination of interviewing, counselling, teaching and supporting skills. Patients and families may require reassurance, as well as repetition and clarification of information. They are likely to feel overwhelmed and anxious. The nurse must adapt the type and level of language and the amount of information shared to achieve effective communication. For many patients and families, the time of diagnosis and treatment planning can be a stressful event in their lives and learning new information or techniques during that interval can be hampered.

During the course of therapy, the nurse maintains an ongoing assessment of the impact of cancer and treatment-related symptoms upon the individual's and the family's quality of life. An ongoing assessment provides a clear picture of how this impact changes over time and what interventions are effective. The assessment needs to include:

- the nature and character of the nausea and vomiting (onset, frequency, severity, etc.)

- the interference with activities of daily living

- the amount of distress the patient is feeling about the nausea and vomiting

- impact of the nausea and vomiting on nutritional status

- impact of nausea and vomiting on fluid balance

- impact of vomiting on metabolic homeostasis

- presence of risk factors such as infection, change in mental status, and the - presence of side effects from antiemetic medications.

Two key areas for ongoing assessment are the effectiveness of prescribed antiemetic and the patient's hydration. Both areas need astute attention. Often the nurse is the health professional who determines with the patient and family exactly what the nausea and vomiting pattern was like during "the last" chemotherapy treatment and exactly how the antiemetic medications influenced it. The dosing schedule for antiemetic therapy must be appropriate for the pattern of nausea and vomiting. For example, a delayed pattern may require coverage for up to a week after the chemotherapy treatment. A close, clear assessment is required to find the effective solutions. Particularly with severe and/or uncontrolled nausea and vomiting, assessment of the fluid balance parameters and the patient's level of hydration is a key nursing responsibility

Based on the data gathered from the assessment, the nurse works with the patient and family to design mutually agreeable goals and care plan approaches. The patient may need help exploring altemative courses of action and sorting out what is most important to him or her. For example, a person may want to continue to work during the course of his treatment but the sedation from the antiemetic medications interferes with his concentration. The planning of care requires that the nurse finds the unique and individually focused combination of interventions for a particular patient. Even if there is a certain amount of test and trial, it is important to stay on top of the issue and make any alterations in medications quickly. The patient needs to maintain hope that the appropriate combination will be found.

An important intervention role for the nurse is the actual administration of antiemetic medications for hospitalized patients (unless the hospital has a self-medication program) and the teaching of those who will be taking their medications at home. Patients and family members need to know how and when the medications need to be taken 
for best effect, how to monitor the effectiveness, and when to call the nurse or doctor for help should it be needed. The patient or a family member could keep a diary to record information about the nausea and vomiting, when antiemetics are taken, and the impact on daily activities (Goodman, 1987). This diary could be part of the ongoing data assessment both in the hospital and the home setting.

There is a range of non-pharmacological interventions that can be useful in managing nausea and vomiting. These interventions include dietary changes (eg. types of foods, timing of meals), environmental alterations (eg. sights, smells) and behavioural and relaxation techniques (eg. distraction, progressive muscle relaxation, imagery). Patients and family members will benefit from learning about these interventions and written material should be provided (Fitch et al, 1991). These types of interventions are within the patient's ability to leam and to control. With practical information, patients and families gain a sense of control. Individuals who have appropriate information about nausea and vomiting, and about measures to prevent and control it become, in essence, partners in care. The interaction they can have with members of the health care team is enhanced. They can work actively with the health care team to find the combination of strategies that will effectively manage their nausea and vomiting. Patients and families can experience empowerment in a situation where they might otherwise feel powerless.

\section{References}

1. Bonadonna, G. Valagussa, P. (1981) Dose response effect of adjuvant chemotherapy in breast cancer. New England Journal of Medicine, 304(1), 10-15

2. Cella, D.F., Pratt, A., Holland, J.C. (1986) Persistent anticipatory nausea, vomiting and anxiety in cured Hodgkin's Disease patients after completion of chemotherapy. Am J Psychiatry, 143(5)1, 641-643.

3. Coates, A., Abraham, S., Kaye S, et al (1983), On the receiving end: Patient perception of the side effects of cancer chemotherapy. Eur $\mathbf{J}$ Cancer Clin Oncol, 191, 203-208

4. Craig, J.B., Powell, B.L. (1987) Review: The management of nausea and vomiting in clinical oncology. Am J Med Sci, 293, 34-44.

5. Donaldson, S.S. (1984) Nutritional support as an adjunct to radiation therapy. JPEN, 8, 302-310.

6. Engelking, C.H., Steele, N.E. (1984). A model for pretreatment nursing assessment of patients receiving cancer chemotherapy. Cancer Nursing, 7 (June), 203-212.

7. Eyre, H.J., Ward, J.H. (1984). Control of cancer chemotherapy-induced nausea and vomiting. Cancer 54, 2642-2648.

8. Fishman, M.L. Thirlwell, M.P., Daly, D.S. (1983) Mallory-Weiss Tears: A complication of cancer chemotherapy. Cancer, 52(11), 2031-2032.

9. Fitch, M., Kulkarni, L., Vincent, L. (1991) The Prevention and Control of Nausea and Vomiting Due to Cancer Therapy: A self-help guide for cancer patients. Prepared by the Canadian Association of Nurses in Oncology.

10. Garry, P.J. (1980) Human Nutrition: Clinical and Biochemical Aspects. Washington: American Association of Clinical Chemistry.

11. Goodman, M. (1987) Management of nausea and vomiting induced by outpatient cisplatin therapy, Seminars in Oncology Nursing, 3(1) Suppl 1, 23-35

12. Grant, M.M. and Padilla, G.K. (1983) An overview of cancer nursing research. Oncology Nursing Forum, 10(1), 58-69.

13. Hoagland, A.C., Bennet, J.M., Morrow, G.R. et al. (1983) Oncologist views of cancer patient non-compliance. Am J Clin Oncol, 6, 239-244.

14. Holroyde, C.P., Reichard, G.A. (1986) Metabolic abnomalities in cancer patients: Anorexia and cachexia. Surg Clin North Am, 66, 947-956. 15. Kaempfer, S.H., Lindsey, A.M (1986) Energy expenditure in cancer: A review. Cancer Nurs, 9, 194-199.

16. Kennedy, M., Packard, R., Grant, M.M. et al. (1981) Chemotherapy-resulted nausea and vomiting: A survey to identify problems and interventions. Oncol Nurs Forum, 8, 19-22.

17. Kris, M.G., Grallon, R.J., Clark, R.A. et al (1985) Incidence, course and severity of delayed nausea and vomiting following administration of high dose cisplatin. J Clin Oncol, 3, 1379-1384.
Evaluating the effectiveness of interventions to manage nausea and vomiting must be done in the context of an overall perspective of the patient's quality of life and all interventions that have been initiated. It is helpful to have regular times to complete such a review not only with the patient and family, but with other members of the health care team. Where possible, standardized measurement tools should be used for symptom assessment and quality of life assessment. Clinically relevant instruments are appearing with greater frequency (Rhodes, 1984).

\section{Summary}

The responses of the patient to cancer-related symptoms and treatment side effects must be of primary concern to oncology nurses. Nurses work collaboratively with other members of the health care team to prevent and/or minimize side effects and their sequelae. Nurses work to reduce symptom distress, enhance patients' self-care abilities and improve patients' ability to cope with symptom occurrence. In particular, nurses can influence patients' experiences with treatment-induced nausea and vomiting by administering effective antiemetic, by offering other non-drug interventions and by teaching patients and families ways to effectively manage these symptoms.

Successful management of treatment-induced nausea and vomiting can have a profound impact on quality of life of the patient and the family.

18. Laszlo, J. (1983) Emesis as limiting toxicity in cancer chemotherapy. In Laszlo, J. (ed.), Antiemetic and Cancer Chemotherapy. Baltimore: Williams and Wilkins, 1-5.

19. Levine, A.M., Richardson, J,L., Marks, G., et al (1987) Compliance with oral drug therapy in patients with hematologic malignancy. $\mathrm{J} C$ lin Oncol, 5, 1469-1476.

20. Lindley, C.M., Bernard, S. and Fields, M. (1989) Incidence and duration of chemotherapy-induced nausea and vomiting in the outpatient oncology population. J Clin Oncol, 7(8), 1142-1149.

21. Lindsey, A.M., Piper B.F., Stotts, N.A. (1982) The phenomena of cancer cachexia: A review. Oncology Nursing Forum, 9, 38-42

22. Merrifield, K.K., Chaffee B.J. (1989) Recent Advances in the Management of Nausea and Vomiting Caused by Antineoplastic Agents. Clin Pharm, 8, 187-199.

23. Nerenz, D. R., Leventhal, H. and Love, R.R. (1982) Factors contributing to emotional distress during cancer therapy. Cancer, 50, 1020-1027.

24. Oberst, M.T. (1978) Priorities in cancer nursing research. Cancer Nursing, 1(5), 281-290.

25. Penta, J., Poster, D., Bruno, S. (1983) The pharmacologic treatment of nausea and vomiting caused by cancer chemotherapy: A review. In Laszlo, J. (ed.), Antiemetic and Cancer Chemotherapy. Baltimore: Williams and Wilkins, 53-92.

26. Pritchard, A.P., Speechley, V. (1989) What do nurses know about emesis? International Cancer News, 1(1).

27. Rhodes, V.A., Watson, P.M., Johnson, M.H. (1984) Development of reliable and valid measures of nausea and vomiting. Cancer Nursing, 7 (Feb), 33-41.

28. Rhodes, V.A., Watson, P.M., et al (1987) Patterns of nausea, vomiting and distress in patients receiving antineoplastic drug protocols. Oncology Nursing Forum, 14(4), 35-40.

29. Rhodes, V.A., Watson, P.M and Johnson, M (1985) Patterns of nausea and vomiting in chemotherapy patients: A preliminary study. Oncology Nursing Forum, 12(3), 42-48.

30. Richardson, J.L., Marks, G. and Levine A. (1988) The influence of symptoms of disease and side effects of treatment on compliance with cancer therapy. J Clin Oncol, 6(11), 1746-1752

31. Wickham, R. (1989) Holistic management of nausea and vomiting caused by chemotherapy. Oncology Nursing Forum, 16(4), 563-574.

32. Whitehead, V.M. (1975) Cancer treatment needs better emetics. New England Journal of Medicine, 293(4), 199-200.

33. Yasko, JM. (1985) Holistic management of nausea and vomiting caused by chemotherapy. Topics in Clin Nurs, 7(1), 26-38. 